\title{
The TPSACK Framework Implementation in Measuring the Technological, Pedagogical, Skills and Content Knowledge by Using Courseware
}

\author{
${ }^{1}$ Roslaili Anuar, ${ }^{2}$ Shahriman Zainal Abidin, ${ }^{3}$ Wan Zamani Wan Zakaria, ${ }^{3}$ Sharkawi Che Din \\ ${ }^{1}$ Faculty of Education, Universiti Teknologi MARA, Puncak Alam Campus 42300 Bandar Puncak Alam Selangor Malaysia \\ ${ }^{2}$ Formgiving Research Group, Faculty of Art \&Design, Universiti Teknologi MARA 40450 Shah Alam Selangor Malaysia \\ ${ }^{3}$ Faculty of Art \& Design, Universiti Teknologi MARA, Puncak Alam Campus 42300 Bandar Puncak Alam Selangor Malaysia
}

rosla206@uitm.edu.my, shahriman.z.a@uitm.edu.my, wanzfssr@uitm.edu.my, sharkawi237@uitm.edu.my

Tel: +60126600475

\begin{abstract}
This study examines the implementation of the TPSACK courseware, which was developed with artistic skills practice to discover the Technological, Pedagogical and Content Knowledge of the Art and Design Education (ADE) students. The courseware was developed based on Dick and Carey Instructional Design Model (2009), which addresses instruction as an entire system, focusing on the interrelationship between context, content, learning and instruction. Respondents from 130 students were gathered to analyze the courseware. Quantitative method was used to conduct a survey which is explored through SPSS. Results show a significant role in integrating technology with specific artistic skills to improve the students' knowledge.
\end{abstract}

Keywords: TPACK framework; TPSACK framework; artistic skills

eISSN: 2398-4287○ 2020. The Authors. Published for AMER ABRA cE-Bs by e-International Publishing House, Ltd., UK. This is an open access article under the CC BYNC-ND license (http://creativecommons.org/licenses/by-nc-nd/4.0). Peer-review under responsibility of AMER (Association of Malaysian Environment-Behaviour Researchers), ABRA (Association of Behavioural Researchers on Asians) and cE-Bs (Centre for Environment-Behaviour Studies), Faculty of Architecture, Planning \& Surveying, Universiti Teknologi MARA, Malaysia. DOI: https://doi.org/10.21834/ebpj.v5iSl3.2553

\subsection{Introduction}

In the $21^{\text {st }}$ century, the rapid emergence of technology has brought a lot of innovations in the field of teaching and learning area. Students can use communication and information technologies for their development in a particular space. In this study, technology interrogation efforts among the Art and Design Education (ADE) students in different dimensions were investigated, and the result showed that effective integration of technology in teaching carries a multi-layer process which further required additional changes at each level. The educators believe that only if the technology is meaningfully integrated with education, it will support learning and teaching practices (Pamuk, 2012). The art teachers must be confident enough to face risk while trying out new techniques and methods and finding ways to improve their teaching style with different concepts (Pérez-Fabello \& Campos, 2007). The profession of visual art teacher has been focusing on a purpose to prepare the new and upcoming generation to adapt the changes in culture with critical, valuable and imaginative with high aesthetic values. The visual art educators must possess high skills in teaching with effective methods to improve the learning quality (Chua et al., 2003). To identify technology readiness among students, the TPACK framework is referred to as the guideline. The development of the TPACK framework has been considered an effective approach,

eISSN: 2398-4287C 2020. The Authors. Published for AMER ABRA cE-Bs by e-International Publishing House, Ltd., UK. This is an open access article under the CC BYNC-ND license (http://creativecommons.org/licenses/by-nc-nd/4.0/). Peer-review under responsibility of AMER (Association of Malaysian Environment-Behaviour Researchers), ABRA (Association of Behavioural Researchers on Asians) and cE-Bs (Centre for Environment-Behaviour Studies), Faculty of Architecture, Planning \& Surveying, Universiti Teknologi MARA, Malaysia. DOI: https://doi.org/10.21834/ebpj.v5iSI3.2553 
which gives positive results. It has been stated that this framework eventually gave positive results in terms of student learning, which motivates the student to learn more.

\subsection{Background of the Study}

The ADE students are required to gain proper artistic skills knowledge which enables them to teach subject matter properly as they are the future visual art teachers. Effective teaching at a higher educational level is crucial to implement for producing students applying higher-order thinking for creating critical design ideas. An expert requires strong knowledge for making knowledgeable capital in the field of technology. According to Koster (2001), teachers must follow the artistic skills to produce visual elements so that they can represent it in the classroom through a digital medium. Hence, the TPACK framework has been improvised to TPSACK with the integration of the skills to investigate the students of Art and Design Education (ADE) Programme, Faculty of Education, Universiti Teknologi MARA (UiTM) technological, pedagogical, skills and content knowledge to establish the newly proposed framework.

\subsection{Problem Statement}

It has been observed that ADE students while interpreting the objective of the subject matter face difficulties in the syllabus. This is due to the reason of low skill knowledge and intense experiences in the profession of teaching. Skill with little artistic factor plays a vital role for a student to think innovatively when implementing the learning and teaching process. According to Koster et al., (2008), the profession of teaching needs teachers to motivate the students in their thinking process to make them think creatively and with different methods. Inducing proper skills and relevant knowledge would enable the students to conduct a meaningful learning and teaching session.

Research conducted about arts and skills knowledge in a secondary school found that some art teachers were not trained mainly in the facilities in arts education and were walking on the traditional way of teaching within the limited available resources. The research also found that art teachers were not even aware of the subject matter properly, which ultimately affected student knowledge. This concluded that teachers were practising their own patterns of teaching. This indicated that teachers who have not gained expertise in skills and art are not aware of what to teach (subject matter) (Chua et al., 2003). Moreover, Hickman (2004), exclaimed that to promote life-long learning art teacher possesses the potential to in cooperating such learning by providing the students with an adequate amount of skills to foster their understanding. For cultivating artistic skills in ADE students, training and guidance play an essential role to be implemented at an early stage. However, Hudson et al., (2010), suggested teachers for professional teaching and learning require the development of certain competencies. Further concluded by Phelps and Maddison (2008), technology has been widely affected the teachers for updating their practices to understand what is happening in the new art environment. The integration of technology with artistic systems makes the atmosphere of the classroom more dynamic.

\subsection{Objectives of the Study}

The objective is to measure the technological, pedagogical, skills and content knowledge through designed TPSACK courseware. The three equally important categories of this framework would be discussed, representing the importance of each component to elucidate the knowledge of the ADE students.

\subsection{Research Questions}

The research questions have been formulated to achieve the objectives of the study by considering the critical questions as constructed below:

1. What is the impact on ADE students learning due to the technological, pedagogical, skills and content knowledge?

2. Is there any positive effect on the development of ADE students' artistic skills due to TPSACK framework?

\subsection{Literature Review}

A study has been conducted by Shulman (1986), after realization of a more logical framework need to learn what students must do in their teaching patterns regarding content knowledge and how they can relate this content knowledge in the curriculum. The need for identifying various ways to integrate this content knowledge in their teaching practices was studied thoroughly by Shulman (1986). Furthermore, his study carried the association between the ability of organization and amount of a subject matter specifically content and what practices to be incurred to teach the content knowledge. According to Cox and Graham (2009), technology pedagogy knowledge can be defined as knowledge related to general pedagogical activities which can be achieved when a teacher practices different way to technologies. Hence, TPACK has been considered a framework that guided the excellent teaching skills with technology, which needs other ways to represent concepts while integrating technologies constructively to teach content skilfully.

Moreover, Mishra and Koehler (2006) in a research conducted on TPACK framework for teachers, PK (pedagogical knowledge) is defined as the knowledge of processes and methods to improve teaching and learning and what effects it cast on educational values. It was also studied that these certain techniques would help students to enhance their knowledge. A study conducted by Harris and Hofer (2009), on instructional activities plans for curriculum types, illustrated pedagogical knowledge that explained knowledge of ideas and concepts to make students learn clearer about the curriculum requirements and the related mistakes they make to learn from it in a specific content of pedagogies. 
According to a study, teaching has been complicated due to the integration of information and communication technology in the era of digitalization. Both the teacher's knowledge and the development of the TPACK require the opportunities to effectively communicate the information and integrate technology with reducing the complexities. Based on a research conducted, reflection has been considered as a strategy, which helps the future teachers for analyzing and identifying the teaching complexities which have incurred during the process (Lu, 2013). These reflective activities for the development of the framework, they need to learn the skills related to analytical thinking.

Research has been conducted on the detailed design of the TPACK development, which elaborates on the student's role when working with technology. The objective of the study was to investigate the integration of information and communication technology in the teaching practices and how students must develop the ICT methods for achieving maximum results (Albion, 2012). According to a study conducted by Mishra and Koehler (2005), respondent's interest in the element of TPACK has increased due to the ideal characteristics in the framework. This understanding was supported by information and communication technology, which served as an instrument for increasing the teacher's progress in the teaching process (Koh \& Divaharan, 2011). Also, it has been reported that modelling of faculty and skills of the computer have been the most important aspects to stimulate the attitudes of teachers.

\subsection{TPACK Framework}

This study has been suggesting the TPACK framework from Mishra and Koehler (2008) that led suggestions on the importance of technological integration with the understanding of proper constructs technology, pedagogy and content knowledge. This framework supported by Mishra and Koehler in providing information has not been considered an adequate framework in delivering information for improving the skills of teachers. Therefore, the artistic skill is added as a factor in the preparation and development of teachers to fulfil the requirements of the ADE students in identifying the development of their artistic skills.

This study has been conducted as an extension of TPACK framework towards TPSACK framework for directing the artistic skills needed in teaching profession for productive lessons and outcomes. Shulman (1987), studied the framework of pedagogical content knowledge (PCK) to provide a clear explanation of the foundation for teachers, implementing pedagogy content knowledge. The framework mainly focused on the connection of ideas from one and another for transforming the understanding of teachers while teaching (Fig. 1).

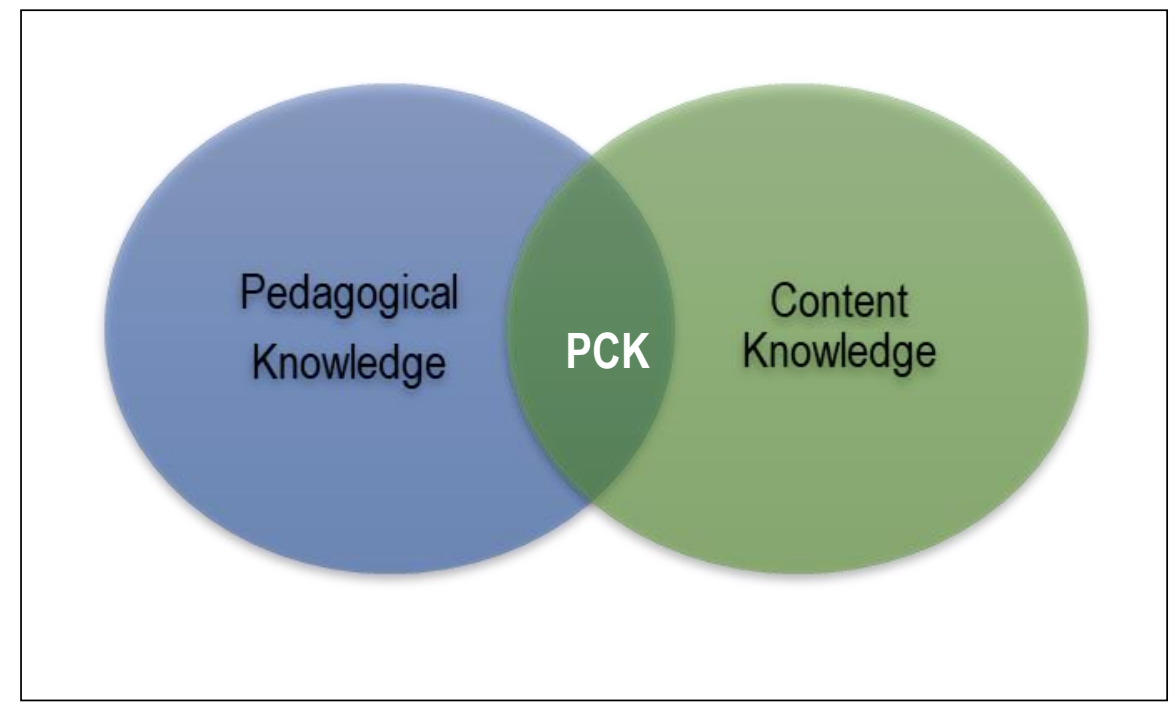

Fig. 1: Shulman's Framework (1987)

(Source: What is Technological Pedagogical Content knowledge (TPACK)? Contemporary Issues in Technology and Teacher Education)

Shulman distinguished between the pedagogical knowledge and the content knowledge where the pedagogical knowledge was related to the understanding the patterns of how to teach and content knowledge referred as an understanding regarding the subject matter. The pedagogical content knowledge referred as a blend of pedagogy and content for teacher understanding and knowledge for delivering the subject matter during learning and teaching process. The knowledge includes knowledge about certain topics of subject matter and how issues can be organized, adapted and represented in the classroom to students to gauge their interest and abilities during the learning phase (Shulman, 1987).

The framework of Shulman's framework has been extended by other scholar's such as Mishra and Koehler who performed a research in which they added technology as one major component in the PCK framework and designed it as a complete TPACK framework in 2008 (Fig. 2). Mishra and Koehler (2006), suggested that the framework TPACK does not merely works on the separate role played by the three components knowledge but a complete understanding takes place when an interplay of relationship exist between them framework further emphasizes that teachers requires various kinds of understanding to make integration of technology successful with positive outcomes in the learning process (Koehler \& Mishra, 2009). 
Based on a source, this framework on the Lee Shulman's work $(1987,1986)$ has been built which has described ways for teachers understanding the technology and pedagogical content knowledge relationship with one another (Mishra and Koehler, 2008). Harris, Mishra and Koehler (2008) further stated TPACK has been emphasizing on the interplay among technologies, specific pedagogical styles, demonstrates the ways teachers understand the technology, curriculum content, pedagogy and content can interact among one another for producing discipline-based teaching effectively while integrating technology (Mishra \& Koehler, 2008). Hence, the framework supports them to adapt the technology effectively and efficiently (Harris \& Hofer, 2009).

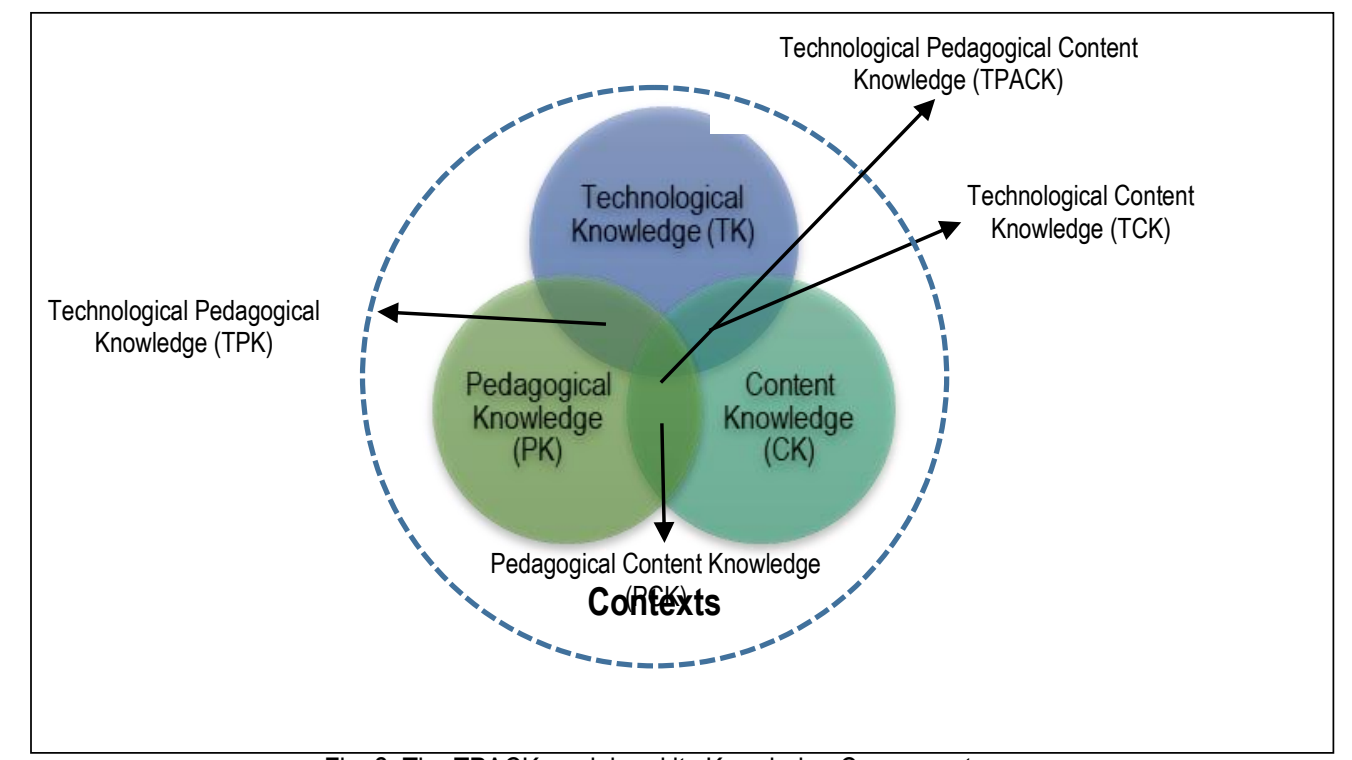

Fig. 2: The TPACK model and its Knowledge Components

(Source: What is Technological Pedagogical Content knowledge (TPACK)? Contemporary Issues in Technology and Teacher Education)

According to Mishra and Koehler (2008), the framework of PCK has been one in which individuals interpret on the subject matter and look for various ways to represent it. It is important for adapting instructional materials for assisting the student previous understanding. About the knowledge it is a component and ability to clear understand how to practice the appropriate methods in a subject while teaching. Furthermore, TCK has been constructed in a way technology and content can influence one and another. Teachers need to understand not only the subject matter but also, they must have a clear understanding of the methods and techniques in which the subject matter through the technological integration can be properly refined. With the use of technological techniques and tools, teachers need to understand what best suit to address the subject matter knowledge in making students learn.

Moreover, TPK has been justifies as an understanding for teachers to learn the patterns of teaching and learning in their professional field with the implementation of technology. This includes understanding the pedagogical affordances and barriers within the range of technological tools as they relate to disciplinarily and developmentally appropriate pedagogical designs and strategies. So, it is must that a teacher understands the constraints of technologies and what practical implications technology can play in the classroom environment. Also, TPK give guidance to teachers for identifying the best possible integration ways in teaching practices.

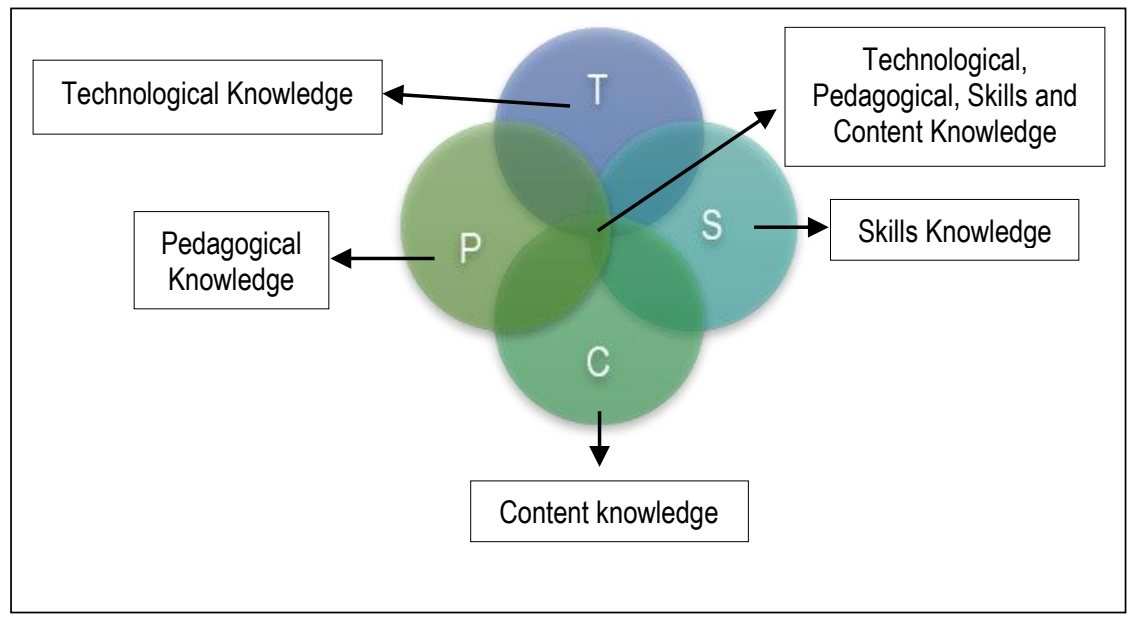

Fig. 3: The Technological, Pedagogical and Content, Skills Knowledge (Source: Theses) 
The represented Fig. 3 is an adaption from the TPACK framework of Mishra and Koehler (Mishra \& Koehler, 2009). The addition of the skill component in the original framework enhances the performance of learning with technology. The components overlapping has been focusing on the technological knowledge (TK), pedagogical knowledge (PK), content knowledge (CK) skills knowledge (SK) and technological, pedagogical, skills and content knowledge (TPSACK). The importance of artistic skills is enhanced to train the ADE students for developing self-efficacy and generating an environment of better art practices. With the indulgence of skills in the framework quality teaching will enhance the artistic perception and aid in the development of consistent competency. The components were highlighted in the TPSACK courseware that has been designed specifically with the artistic skills practice to identify the ADE student's skills knowledge development. For example, see Fig. 1 and Fig. 2 below. The artistic skills knowledge has been playing a significant role in the art profession particularly which requires certain artistic skills in creativity and these skills aids in bringing more creativity in arts. The process has gained importance as it provides the ADE students with certain direction for generating and developing their ideas based on observations. Based on the framework, the ADE students needed to acquire expertise in planning, decision making, critical thinking and time management for their personal skills development.
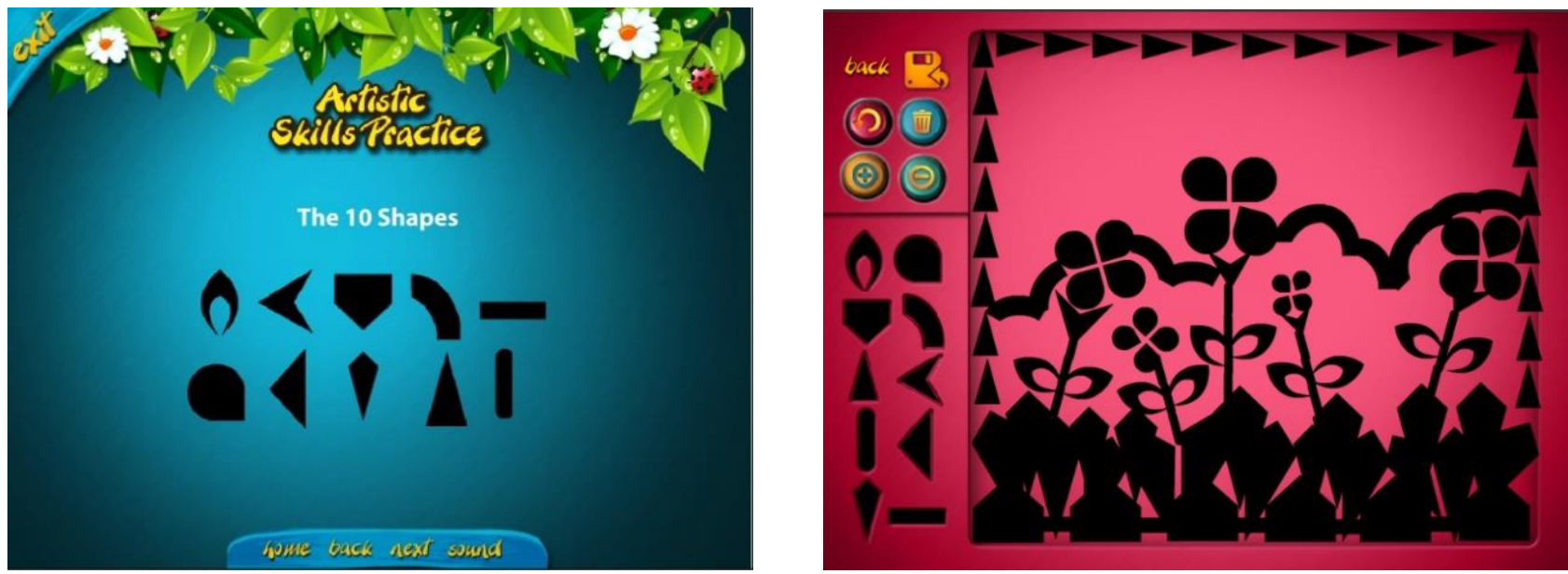

Fig. 4: The artistic skills practice in the TPSACK courseware

(Source: Theses)

\subsection{Methodology}

Methodology that has been applied in this research is based on quantitative approach to investigate the sample developed framework responses. Primary objective of this research is to gauge the ADE student's competency while integrating technology, pedagogy, skills and content knowledge. Data has been collected with the help of TPSACK questionnaire during the application of qualitative approach. Multivariate techniques within quantitative research methodology are significantly used for assessing the reliability and validity of results. In relation to this, the following study has implied the quantitative primary research design to assess the impact of the courseware on skills development.

\subsection{Quantitative Method}

Questionnaire had the focus on quantitative method. Design of survey was to give the numeric and quantitative description of attitudes, description, opinion and trends of a population by learning a sample of that population (Cresswell, 2003). To gather the quantitative data, survey implementation of TPACK has been completed (Schmidt et al. 2009). For creation of new survey, combination between Georgia Assessment for the certification of Educators (GACE, 2007) and TPACK has been made, the purpose of TPSACK was to figure out the ADE students pedagogical, content, technology, artistic skills and content knowledge.

\subsection{Findings}

The questionnaire was collected and translated into descriptive statistical analysis format to show the results. Results are tabulated and described in the Table 1 to identify the technological, pedagogical, skills and content knowledge of the ADE students. Findings of the data collected has shown a positive result in the evaluation involving the TPSACK of the students. The description of effects regarding the ADE students TPSACK has been figured out by the detailed assessment that has created accordingly to TPSACK framework in comparison with the calculations of success of the ADE students to enhance their creative ideas. The final figures carry standard deviation, mean, percentage and frequency of the data. The mean score range is obtained by the evaluation of mean value having different ranges i.e. low, medium or high. These ranges were used by Chua et al, (2003). 
Table 1. Total distribution in the evaluation of the TPSACK courseware

\begin{tabular}{|c|c|c|c|}
\hline No & Items & $m$ & $S D$ \\
\hline & TK (Technology Knowledge) & & \\
\hline Q1 & I can learn technology easily. & 4.04 & .95 \\
\hline Q2 & I keep up with important new technologies. & 3.97 & .71 \\
\hline Q3 & $\begin{array}{l}\text { I have had sufficient opportunities to work with different technologies. } \\
\text { CK (Content Knowledge) }\end{array}$ & 3.76 & 1.06 \\
\hline Q4 & I have sufficient knowledge about VAE subject & 4.41 & 1.09 \\
\hline Q5 & I can use a visual way of thinking. & 4.51 & .63 \\
\hline Q6 & $\begin{array}{l}\text { I have various ways and strategies of developing my understanding of VAE subject } \\
\text { PK (Pedagogical Knowledge) }\end{array}$ & 3.51 & 0.96 \\
\hline Q7 & I know how to assess student performance in a classroom. & 4.65 & .414 \\
\hline Q8 & I can adapt my teaching style to different learners. & 4.34 & .505 \\
\hline Q9 & $\begin{array}{l}\text { I am familiar with common student understandings and misconceptions. } \\
\text { SK (Skills Knowledge) }\end{array}$ & 3.24 & .615 \\
\hline Q10 & I understand the elements of art and principles of design and their use in works of visual art. & 4.25 & .564 \\
\hline Q11 & I understand the visual arts as a form of communication & 4.74 & .355 \\
\hline Q12 & $\begin{array}{l}\text { I understand the basic principles of analysis, interpretation, and evaluation in works of visual art. } \\
\text { Artistic Skills Development }\end{array}$ & 3.64 & .465 \\
\hline Q13 & I have developed a good artistic skill after using the test & 3.76 & 1.01 \\
\hline Q14 & I can think creatively after taken the test & 4.81 & .94 \\
\hline Q15 & I have improved my artistic skills ability after using the test & 4.51 & .63 \\
\hline
\end{tabular}

\subsection{Discussion}

The results tabulated in Table 1 indicated that majority of ADE students found their TPSACK as shown relevant and accurate development in terms of the TK, PK, SK and the CK. They also agree that the content of the courseware which was developed with the artistic skills practice is up to date and challenging to them. Such response could be because the respondents have similar learning and background knowledge of the arts and design education. The ADE students also indicated that the integration of the artistic skills practice is distinctively unique and have been brilliantly composed to help in shaping their artistic skills. In relation to the artistic skills development, the ADE students agreed that their skills knowledge has increased and they are able to create spontaneous artwork with the provided artistic skills practice in the TPSACK courseware. The respondents also agreed that the tools provided allow for smooth navigation of the artistic skills practice, and they can interact with the devices in ease. Majority of the students responded that practising the artistic skills via courseware is fun. The students also agreed that it is easy to use and navigate the courseware. It takes them only minimal time to understand how the shapes from the artistic skills practice being operated. Once the students could comprehend all the information provided, they managed to create an artwork with various ideas.

\subsection{Conclusion and Recommendations}

This study has described the process of identifying the technological, pedagogical, skills and content knowledge (TPSACK) by using the courseware and issues relating to the efficacy elements to support the need for the study. The focus of this study is on improving the technological, pedagogical, skills and content knowledge. The ADE students by using courseware as the medium of instruction have been addressed appropriately. This study has concluded that the design of courseware based on the framework of TPSACK to hasten the artistic skills acquisition for knowledge development. Findings show that there is a significant difference exist between the proficiency of computer as a support tool to enhance the skills. Moreover, the knowledge test, along with the exercise, has increased the interest of the ADE students. The recommendations which help improve this study are the critical and creative skills of thinking should be integrated with the nature of the activities that were provided in the courseware. These activities will help in solving the problem through their skills and knowledge. Elements and principle of arts were used to the test the respondent at that moment which is the foundation of the art education.

\section{Acknowledgements}

The authors would like to thank the University Teknologi MARA (UiTM) in giving the scholarship as this study is based on the PhD research.

\section{References}

Alsofyani, M.M., Eynon, R. and Majid, N.A. (2012). A preliminary evaluation of short blended online training workshop for TPACK development using technology acceptance model. TOJET: The Turkish Online Journal of Educational Technology.

Alrasheedi, M., \& Capretz, L. F. (2018). Determination of critical success factors affecting mobile learning: a meta-analysis approach. arXiv preprint arXiv:1801.04288. 
Al-Shami, S., Aziz, H. \& Rashid, N. (2018). The adoption of MOOC utilization among undergraduate students in Universiti Teknikal Malaysia Melaka (UTEM). Journal of Fundamental and Applied Sciences, 10, 2634-2654.

Berry, F. S., \& Berry, W. D. (2018). Innovation and Diffusion Models in Policy Research. In Theories of the policy process (pp. 263-308). Routledge

Chua Yan Piaw, Sharifah Md. Nor, Naim B. Mohd \& Wan Zah Wan Ali . (2003). Kreativiti Guru Pendidikan Seni. Pertanika J. Soc. \& Hum. 11(1): 11-17 (2003). Universiti Putra Malaysia Press. Article retrieved December 12, 2009 from http://psasir.upm.edu.my/3412/1/Kreativiti_Guru_Pendidikan_Seni.pdf

Cresswell, J.W. (2003). Research design qualitative, quantitative and mixed-method approach. Second EditionSage Publication, Inc

Jang, S.J. and Chen, K.C. (2010). From PCK to TPACK: Developing a transformative model for pre-service science teachers. Journal of Science Education and Technology.

Kim, E., \& Corcoran, R. P. (2018). Factors that influence pre-service teachers' persistence. Teaching and Teacher Education, 70, 204-214.

Koehler, M. and Mishra, P. (2009). What is technological pedagogical content knowledge (TPACK)? Contemporary issues in technology and teacher education.

Koehler, M.J. and Mishra, P. (2005). What happens when teachers design educational technology? The development of technological pedagogical content knowledge. Journal of educational computing research.

Kumar, R. (2019). Research methodology: A step-by-step guide for beginners. Sage Publications Limited.

Mishra, P., Koehler, M.J. and Henriksen, D. (2010). The seven transdisciplinary habits of mind: Extending the TPACK framework towards 21st-century learning. Educational Technology.

Mena, J., Hennissen, P., \& Loughran, J. (2017). Developing pre-service teachers' professional knowledge of teaching: The influence of mentoring. Teaching and teacher education, $66,47-59$.

Ochshorn, S. (2018). Writing History: A Teacher's Guide to the History of Language Technology and Museum Practice.

Pamuk, S. (2012). Understanding preservice teachers' technology use through the TPACK framework. Journal of Computer Assisted Learning.

Pérez-Fabello, M.J. and Campos, A., 2007. Influence of training in artistic skills on mental imaging capacity. Creativity Research Journal.

Papanikolaou, K., Makri, K., \& Roussos, P. (2017). Learning design as a vehicle for developing TPACK in blended teacher training on technology-enhanced learning. International Journal of Educational Technology in Higher Education, 14(1), 34.

Raman, R., Vachharajani, H., \& Achuthan, K. (2018). Students motivation for adopting programming contests: Innovation-diffusion perspective. Education and Information Technologies, 23(5), 1919-1932.

Rodriguez, M., Boyer, S., Fleming, D. \& Cohen, S. (2019). Managing the Next Generation of Sales, Gen Z/Millennial Cusp: An Exploration of Grit, Entrepreneurship, and Loyalty. Journal of Business-to-Business Marketing, 1, 1-13.

Rupietta, C., \& Backes-Gellner, U. (2019). How firms' participation in apprenticeship training fosters knowledge diffusion and innovation. Journal of Business Economics, 89(5), 569-597.

Scott, S. \& Mcguire, J. (2017). Using Diffusion of Innovation Theory to Promote Universally Designed College Instruction. International Journal of Teaching and Learning in Higher Education, 29, 119-128. 